13

\title{
SMEs in Supply Chain: \\ a Supplier Evaluation Model and some empirical results
}

\author{
P. Morlacchi, S. Pavesi, A. Savoldelli \\ Consorzio MIP-Politecnico di Milano, via Fucini 2, \\ 20133 Milano, Italy, +39-2-236918.1, +39-2-23691820 \\ pieram@mailer.mip.polimi.it,spavesi@mailer.mip.polimi.it, \\ alberto@mailer.mip.polimi.it
}

\begin{abstract}
The paper aims at providing a Vendor Assessment model which can be useful to evaluate potentialities and capabilities of suppliers . The assessment of a supplier's capacity to undertake supply relations is carried out by means of a process-based view of the company. It is assumed that effective and integrated processes contribute to a company's capacity to develop satisfactory relations within the supply chain in which it operates. The assessment of each process is based on the measurement of its assets or variables of state: human, technology and finance resources and organisational skills. The analysis has been carried on by a survey to verifying the potential of southern Italian sub-contractors to respond to the needs of commissioning companies in the machine tools and special purpose machines industries. The ultimate aim of the study, which is funded by the European Union and the Institute for Industrial Promotion, is to create new client-supplier relations between large companies in the machines sector and small and medium enterprise (SME) suppliers in southern Italy.

Although the study has not yet reached an acceptable level of statistical significance, the in-depth analysis of approximately 200 suppliers in the machine sector does, nevertheless, indicate the strengths and weaknesses of sub-contraction in southern Italy, and suggests possible ways in which those companies still without sufficient skills to satisfy the needs of potential commissioners can improve.
\end{abstract}

Supplier assessment, process analysis

\section{Keywords}




\section{INTRODUCTION}

The markets globalisation forces the companies to re-organise internal and external activities, in order to satisfy the requirements of a world-wide marketplace. There is a tendency of the companies to move towards a more efficient use of their own, internal resources, which become a pre-requisite for success, as well as to the correct identification and satisfaction of market needs (De Maio and Maggiore, 1992; Lamming, 1993). Among the various ways which can be pursue by a company in realising its competitive strategies, supplier management appears to play a fundamental role. The choice, assessment and promotion of suppliers allow a company not only to improve its own performances, but also the ones of the supply chain it belongs to (Hartley and Choi, 1996; New, 1996).Therefore, to undertake successful relations which can continue and became steady over time, suppliers must have particular features. A simple analysis of the product produced is no longer a sufficient means of assessment, and variables linked to company internal capabilities increasing their importance (Ellram 1990).

For this reason, in this work, the evaluation of a supplier's capacity to undertake supply relationships is based on an assessment of their operational, strategic and organisational processes, in order to verify the capabilities not only to manage its own internal affairs, but also to interface and interact up and down the supply chain (Bartezzaghi et al., 1994; New, 1996). The paper illustrates how the analysis of company processes and relative assets or variables of state (human, technological, financial resources and organisational skills) allows a customer to select the supplier best able to satisfy its specific needs. On the other hand, the identification of the critical variables, which have the greatest impact on the results of company processes, indicate to the supplier, the necessary improvements to move from simple commercial relations with its customers, to more long-term, articulated and complex relationships, identifying a possible growth path for the supplier companies.

The main purpose of this article is to present a supplier evaluation model developed and some empirical results pointed out from a survey verifying the potential of southern Italian suppliers to respond to the needs of buyer companies in the machine tools and special purpose machines industries. This work is carried out of a part of a project promoted by the European Community and the Institute for Industrial Promotion which seeks to create new client/supplier relations between large companies in the machines sector and suppliers in southern Italy. The end customer of supply chain is a big-medium sized firm, while intermediate suppliers/customers are small and medium sized enterprises (SMEs).

The articulation of the work is the following: after a brief review of recent literature about supplier selection criteria and techniques, first of all the methodology used is summarised; then the supplier evaluation model is presented; finally, data analysis results are proposed. 


\section{LITERATURE REVIEW}

According to recent literature the selection and evaluation of supplier are really relevant questions: the right choice not only influences the performances of current purchase, but it more and more determines the overall company performances. Moreover in a turbulent market finding the right partner is not so banal: the typology of selection criteria goes beyond traditional performance measurement and often requires the assessment of intangible factors, attitudes and potentialities. Then, the number of the variables to measure is really increasing as the investigation focus moves from product/service performances to company attitudes. As the relevance and complexity of the question it is important to point out how recent literature considers two different problems: first of all the problem of the evaluation tool or technique which can help in aggregating the numerous variables measured and so providing a rating of suppliers, and then which are the right information to collect and elaborate in order to satisfy the requirements of the customers.

About the techniques, some different approaches have been considered and their main characteristics have been reported in Table 1.

Table 1 Some techniques for supplier evaluation

\begin{tabular}{l|l}
\hline Study & Model \\
\hline $\begin{array}{l}\text { Timmerman } \\
1986\end{array}$ & $\begin{array}{l}\text { Categorical approach: it rates suppliers on a number of equally } \\
\text { weighted factors } \\
\text { Cost ratio approach: it evaluates the costs associated with } \\
\text { dealing with a certain supplier } \\
\text { Linear averaging: it rates supplier on a number of different } \\
\text { weighted factors } \\
\text { Payoff matrix which evaluates potentialities of suppliers in } \\
\text { different probable scenarios }\end{array}$ \\
$\begin{array}{l}\text { Soukup 1987 } \\
\text { Thompson }\end{array}$ & $\begin{array}{l}\text { The approach rates suppliers on a number of differently weighted } \\
\text { factors }\end{array}$ \\
$\begin{array}{l}\text { Weber and } \\
\text { llram, 1992 }\end{array}$ & $\begin{array}{l}\text { Multi-Objective Programming (MOP): the supplier selection } \\
\text { decision is solved as a multi-objective problem, identifying the } \\
\text { "best-compromise solution" }\end{array}$ \\
$\begin{array}{l}\text { Mohanty and } \\
\text { Deshmukh } \\
\text { (1993) }\end{array}$ & $\begin{array}{l}\text { AHP: The decision maker develops a hierarchical structure of the } \\
\text { factors in the given problem and provides judgements about the } \\
\text { relative importance of each of these factors and ultimately specifies } \\
\text { a preference for each decision alternative with respect to each } \\
\text { factor. }\end{array}$ \\
\hline
\end{tabular}


Timmermann (1986) discusses three approaches for the supplier evaluation: categorical, cost ratio and linear average or weighted-point method. Categorical approach is really easy and cheap to use but it is based on personal and subjective judgement and does not create a priority among criteria as they are equally weighted. Cost ratio method on the other side is more objective, but it is really complex to implement because it requires a complete cost accounting system. At least linear averaging method, is more objective than a categorical method and the criteria are weighted by their importance, but it requires great attention in defining these weights.

Soukup (1987) proposes a payoff matrix showing the supplier potentialities in different scenarios: it requires to clearly quantify the probabilities of different outcomes and the performances of the suppliers for every scenario.

Thompson (1990) discusses a weighted point method associated with a simulation technique (Monte Carlo) to include uncertainty.

Mohanty and Deshmukh (1993) try to apply AHP techniques to supplier selection problems. This approach presents several advantages: it allows to incorporate both tangible and intangible factors which can be disaggregated in more meaningful and quantifiable variables, the model is really transparent to users, can be easily applied iteratively, it gives flexibility in verifying the subjectivity of factors, sensitivity analysis can be incorporated, it is easily adaptable to new situations and at least some risk factors can be included. In any case it is clear that including too many variables in the model can increase complexity of the procedure.

The other topic concerns the supplier selection criteria. Different approaches have been followed in literature to analyse this particular question. In particular, starting from Dickson (1966), many papers (Soukup, 1988; Weber et al, 1991; Willis and Huston, 1992; Stamm and Golhar, 1993; Mendez and Pearson, 1994) have pointed out how quality, delivery, service and price seem to drive the supplier selection decision. Even if the individual weighting and relevance of the factors vary according to buying situation or product characteristics (Wilson, 1994; Kauffman, 1994) the focus of the traditional perspective remains cost reduction. Other studies (Ellram, 1990; Esposito and Lo Storto, 1992; Nassimbeni et al.1993), stress how traditional performances do not provide complete and reliable information in selecting suppliers mainly when the relationship to be established becomes longer and closer. In other words as the mutual commitment and the sharing of risk and benefits orientation required to both the parties increase, it is very restrictive just considering supplier's performances in the assessment activities: the focus on current products does not allow to understand supplier potentialities and future direction which become fundamental with the long term orientation of the relationship. On the other side some difficulties arise when such type of criteria are considered: first of all the measurability as they refer to both qualitative and quantitative variables; and then the scope and cost of the information as data about the whole company should be collected. While the first problem could be partially solved through the choice of an adequate selection tool, which can combine both quali-quantitative factors, the second point is more related 
to the content of the information. Going beyond performances and investigating supplier's processes requires higher costs in identification and collection of the right information and more risk in sharing internal data which can be only justified by a long term, closer and win-win relationship.

Moreover not so many authors deeply analyse which are the right factors useful to evaluate the potentiality of suppliers. The main contributes highlight how it could be related to the capability of managing the technological and operative interface of the dyadic relationship as capabilities, and technologies mainly referred to design and manufacturing (Weber and Ellram, 1990) processes, the organisational culture and strategic coherence (Esposito and Lo Storto; 1992; Kolay, 1993), feeling of trust (Landeros et al., 1995; Smeltzer, 1997).

The model presented in this paper tries to provide a complete and versatile supplier evaluation tool which can assess both output measures and potentialities and then aggregating them in order to rate different supplier according to customers' priorities and needs.

\section{METHODOLOGY}

The methodology is based on both a theoretical and an experimental approach: an empirical study on 200 small and medium sized supplier firms and 25 buyer companies has been combined with a theoretical approach on this research.

First of all, in order to determine the characteristics of the demand in the machines sector, a survey on the methods used by commissioning companies to assess and select their suppliers was carried out. The heads of purchasing of 25 companies were interviewed and structured questionnaires were filled in giving details of the procedures and selection criteria adopted with respect to suppliers. The survey points out that purchasing managers assessment systems are focused on performance measures relating to quality, service and cost of the product, but "if buyer-supplier relationships are to be developed and advanced in practice, methods of assessment suppliers must reflect the new requirements" (Lamming, 1996).

The focus of the supplier evaluation model proposed in this paper is to find and translate subjective factors into effective and measurable firm's assets (Kolay, 1993). This leads to the development of a process-based model, describing and evaluating the key processes, that can be seen a major importance for determining suppliers present and expected future performances and/or capabilities. Taking a top down approach, a supplier firm is viewed as a set of business processes; identifying the inter and intra-companies processes, the supplier firm is modelled by the physical, administrative, managerial and financial processes which carries out to develop its activities of designing, manufacturing, selling, delivering and servicing its product. To be effective, each process use a number of resources or enabling factors: using a hierarchical method a detailed resources-based view model of each process is developed. So a framework for measuring and evaluating 
the supplier capabilities has been developed and it will be illustrated in the next section of the paper.

First validation on the model has been requested to the buyers of customer companies with face to face interviews. The survey also pointed out that, depending on the type of relationship, the type of commodity, part or service purchased, operational processes are better assessed, because they are believed to be better correlated to product performance. In fact just few of respondents consider important the other types of processes: this confirms how it's hard for buyers to abandon old habits and traditional approaches to purchasing, also when they try to develop more co-operative relationship.

The developed model has been then applied and used to processed data collected through a survey on 200 suppliers SMEs located in Southern Italy and 25 customers companies in the machine tools and special purpose machines industries. A descriptive analysis on supply system has been developed and some findings are pointed out: the aim is to identify the potential of Southern Italian SMEs to undertake supply relations which satisfy the demand of customer companies in a particular industries, i.e. machine tools and special use machines. To this end, the study seeks to highlight the distinctive ability of each supplier analysing its processes. After a descriptive analysis to better understand the data, a cluster analysis was used to uncover homogeneous groups or classes of companies with the same production, innovation and organisational/managerial capabilities. Then a ANOVA is performed to investigate differences among groups of firms. This allowed to identify classes of firms, characterised by some processes profiles. Those profiles can provide information on strengths and weakness of every class and provide to each firm a sort of "self-assessment" on the significant areas of review to improve overall performance. Identification and improvement of critical areas is also a requirement for every supplier firm to evaluate and develop advantageous relationships with its customers. Action for improvement can be adapted to the role that a firm has in a supply chain and specific relationships must be targeted depending on the type of commodity, part or service that is purchased, functional and organisational structures of firms involved (Lamming, 1996). This is a requirement to improve the overall supply chain performance (Harland, 1996).

The model illustrated in the next paragraph can be used for the selection of suppliers for undertake, develop and manage a long-term relationship based on their present capabilities and their proven ability to continually improve their performance, following the commitments of customers companies.

\section{THE MODEL}

The framework for measuring and evaluating the supplier firm is developed using a process-based approach. A company is viewed as a set of operational, strategic and managerial processes, the design and management of which allow and determine firm's strategy and its performances. The conceptual scheme of the model is 
illustrated in Figure 1, where can be showed the key processes identified (inter and intra company processes) and their outcome (output measures and financial position). We have grouped the processes into operational, strategic and organisational, according to the type of prevailing activity (Ostroff and Smith, 1992; Edwards and Peppard, 1994).

The assessment of the supplier may concentrate exclusively on the external performance of products/services and the financial position, which are more easily and immediately measured, as they have a direct impact on the client, or involve an analysis of internal features. The latter, indicated with reference to processes, are more difficult to identify and measure, but are more representative of its present and expected future capabilities. Furthermore, as the scheme highlights the principal operational, strategic and organisational processes, it emphasises suppliers capacity not only to manage their own internal affairs efficiently, but also to interface and interact up and down the supply chain with appropriate resources and procedures.

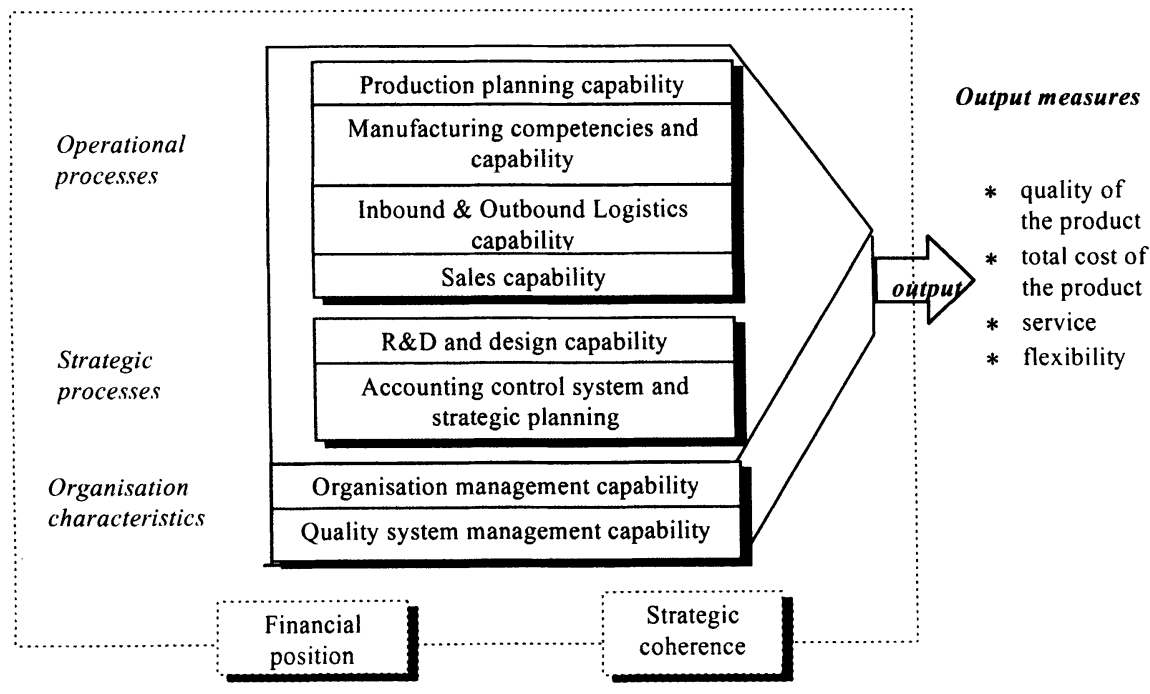

Figure 1 The conceptual scheme of the potential suppliers evaluation model.

The model focuses on evaluation and modelling of processes generating external performances of a firm: the so-called "output measures". In the case of evaluation of potential supplier, processes analysis has a predicting character about future capabilities to supply a product/service suitable to cost, quality, flexibility and service requirements. Such output measures, if disposable, could even aid to complete supplier evaluation or allow to test the model output reliability. The model also includes economical-financial characteristics, a sort of passed reference about supplier capabilities, as regards solidity, productivity and efficiency, which 
are complementary to processes analysis. The model structure is represented in Figure 2.

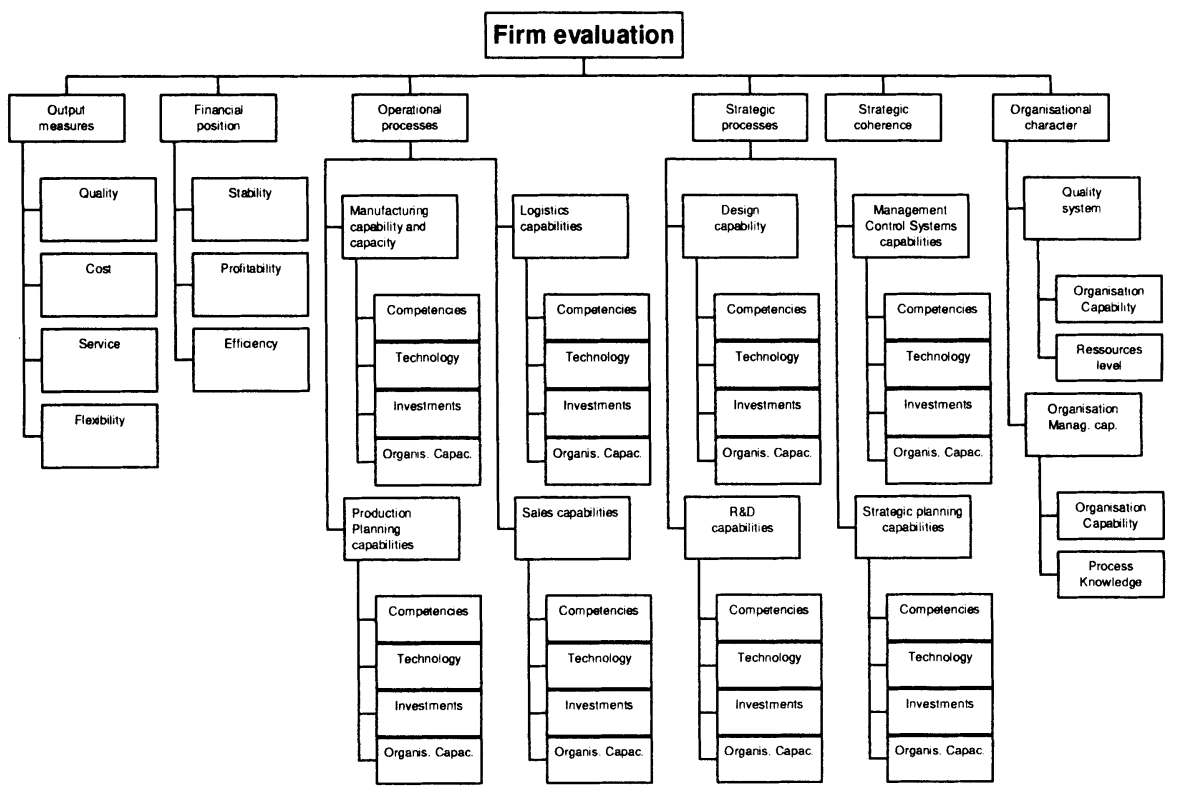

Figure 2 The hierarchical and modular structure.

The structure of the supplier evaluation model present two main characteristics:

\section{Hierarchy}

Given the complexity of "supplier evaluation concept" a hierarchical method is used: company capacity to undertake supply relations is measured with reference to the quality of its processes. In turn, the effectiveness and efficiency of these processes are assessed by the model by means of the measurement of variables of state or assets referring to human, technological, financial and organisational skills (Hamel and Prahalad, 1990; Grant, 1991; Amit and Shoemaker, 1993). These complex variables are further modelled up to find simple indicators that can be measured in the field (Saaty, 1986). The quali-quantitative data amount has been aggregate using fuzzy logic until processes level, then a weighted-point method is applied to determine the final supplier evaluation. Each customer can put his weight vector into the hierarchical structure, getting out a customerized and transparent supplier evaluation (Mohanty and Deshmukh, 1993; Klir, 1995).

\section{Modularity}

For each client-supplier relation the content exchanged and the time scales differ, so the variables emphasised in the assessment of the supplier reflect the specific 
needs of each. In order to make the assessment of suppliers transparent, adaptable and modifiable with respect to the needs of individual customer companies, the model is structured in modules (individual processes, economic and financial features and output measures) which take on varying importance with the different relations. The modules are aggregated by the weights provided by each commissioning company, which reflect the relative importance for the latter of the different modules in the assessment of a potential supplier. The weightings are generally variable, both in terms of the type of relation which the customer company wishes to enter with the supplier and of the specifics of the customers company.

The development of a detailed view of each process involved an examination of the literature on each business process, to identify the indicators of the characteristics of good practice in processes. So we constructed a hierarchy of characteristics of good processes, representing the inter and intra processes integration, their customer orientation, the right level of automation and Information Technology, human resources quality development and management and continuos improvement.

To explain the model logic and characteristics one of the processes is described in detail in appendix.

In general, the model measures the processes quality highlighting the suppliers strength and weakness points: the customer can so discover and evaluate the supplier core capabilities in order to undertake and develop a specific relationship.

The model have to be effective in use, so has been applied and tested through a survey described in the following section.

\section{THE SURVEY}

The model has been applied and used to process data collected through a survey on 200 suppliers SMEs located in Southern Italy and 25 customers companies in the machine tools and special purpose machines industries (Pavesi and Savoldelli, 1997; Morlacchi and Savoldelli, 1997). The main aim was to identify the potential of Southern Italian SMEs to undertake supply relations which satisfy the demand of customer companies in a particular industries, i.e. machine tools and special use machines. As previous observations point out, the model allows to use information both from the supply and the demand side to match the needs of the commissioning company with the structure and potential of individual suppliers. Data were collected by means of an empirical survey of 185 case studies of the supply and 25 of the demand.

The following sections give, therefore, a more detailed analysis of the two sample groups, i.e. the customers and suppliers companies. 


\section{Analysis of the customers companies}

The sample of commissioning companies includes 25 organisations in the machine tools and special purpose machines sector. Each commissioning company was selected on the basis of the interest shown in establishing relations with potential sub-contractors in southern Italy. Some of the companies already have plants and/or suppliers in southern Italy, while others are examining the possibility of working with southern suppliers in the future. The empirical survey of the customers companies is based on 25 case studies. Interviews with the heads of purchasing outline the present situation and future trends in supply. The result is a picture of supply policy in the sector in terms of existing supply relations (the number, content, type and stability of relations, main areas of relationship) and the criteria for selecting and assessing suppliers.

The most interesting element is the growing interest among commissioning companies in developing collaborative relations with a number of suppliers. This is one aspect of a more general and widespread process to rationalise and select suppliers which is currently underway in the majority of industrial companies. As a result, the question of supply has changed from a short-term operational choice to one of long-term, strategic significance. In some cases, the area of interaction between commissioning company and supplier is broadened, the type of relation changes and the supplier becomes a co-maker in operational processes or, occasionally, in the commissioning company's strategic choices. Customers companies generally request not only production skills from their suppliers, but also management, organisational and quality control skills or even ability in project management and innovation. In return, they guarantee stability in supply orders and a greater exchange of information and know-how than in the past, which may start off a process of growth for the suppliers.

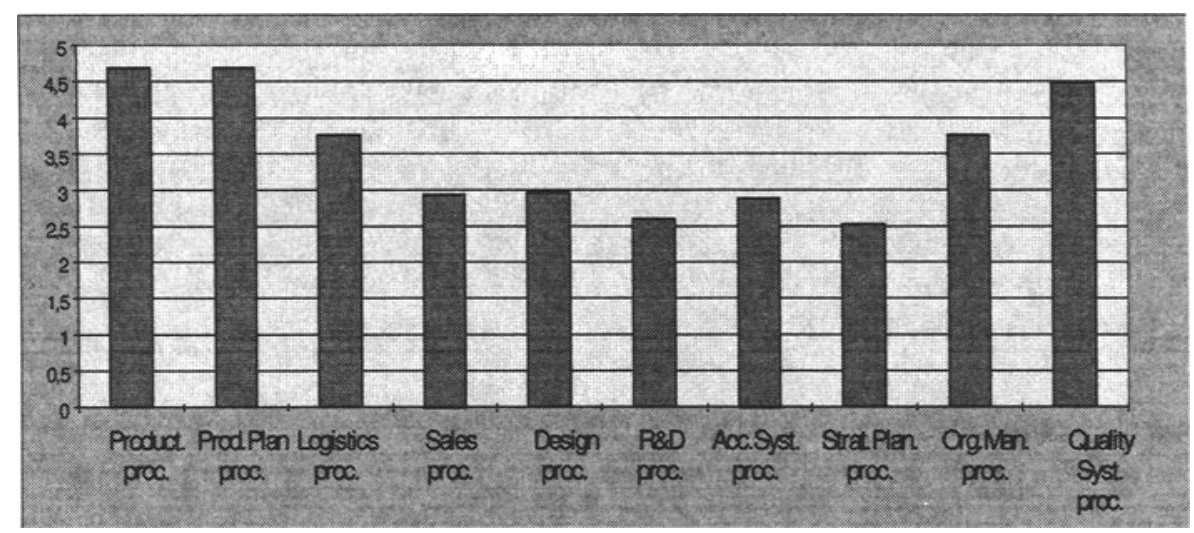

Figure 3 The average weightings vector of customers companies.

For this reason a "weight vector" has been requested at each customers companies, to understand the importance degree of different parts of the model, but in 
particular focusing the analysis on the processes. The weights are generally variable and analysis below uses an "average weights vector", derived as the average of the weights vectors obtained from the customers companies. The average weighs vector smoothes out the contingent aspects of individual companies in favour of the general trend of the demand for supply which is translated into an assessment of company processes and their relative importance, as illustrated in the figure below.

The following section gives a classification of the suppliers, analysing which of their characteristics underpins their potential with respect to the average needs of commissioning companies.

\section{Analysis of the sub-contractors}

The sample of suppliers includes 185 SMEs in Southern Italy with clients in the machine tools and special purpose machines sector. Although this sample is not a statistically significant distribution of the supply system in southern Italy, the number of companies included does allow the main features and current trends to be described.

The supply system in Southern Italy is extremely varied and can be viewed as a continuous flow of supply and sub-contraction, in which, alongside provision of skills and/or specialities, there are complex and developed forms of subcontracting. The sample includes companies which can perform either as suppliers or sub-contractors depending on the product type considered (with reference to the objectives of the project on which this study is based).

The survey unit was the plant (which for SMEs is the individual company itself). A structured questionnaire was developed to collect the data. It was administered face to face to the management group of every supplier firm, with interviews conducted in factory side. The respondents were requested to give also documents and other information by means of phone calls.

The 185 suppliers were identified from an initial group of 3000 companies primarily on the basis of indications from potential commissioning companies, industrial associations and chambers of commerce, but also from the list of main suppliers in southern Italy in terms of turnover. The suppliers to be analysed were selected by reference to geographic position (located in southern Italy), product type (supply to clients in the machine tools and special purpose machines sector) and size (more than 10 employers and turnover above 1 billion ITL).

The tables below give some of the characteristics of the companies analysed, e.g. division by employee classes (Table 2) and main client type (Table 3).

An initial qualitative analysis revealed that the sample includes different types of supply ('to specification' and 'of commercial components') and of sub-contraction (skills, specialities and developed). Moreover, the suppliers are at different levels in the supply chain, making it possible to observe the behaviour of medium size companies which are generally on the first levels, as well as that of smaller companies which, in the main, are further down the chain. 
Table 2 Employee classes

\begin{tabular}{cc}
\hline Employees & Frequency \\
\hline$<20$ & $25 \%$ \\
$21-50$ & $40 \%$ \\
$51-100$ & $12 \%$ \\
100 & $21 \%$ \\
\hline
\end{tabular}

Table 3 Main client type

\begin{tabular}{cc}
\hline Client type & Frequency \\
\hline regional & $25 \%$ \\
National & $57 \%$ \\
International & $18 \%$ \\
& \\
\hline
\end{tabular}

\section{RESULTS}

The aim of the following analysis is to identify the potential of southern Italian SMEs to undertake supply relations which satisfy the demands of commissioning companies in a particular sector, i.e. machine tools and special purpose machines.

Applying the model each company received a final points score as the weighted sum of the scores for the individual processes, in turn measured with reference to the quality of the assets employed. This produced a ranking of the suppliers, both in terms of the preferences of each individual customers company and of the average preferences of all the commissioning companies involved in the study. A first descriptive analysis of the ranking based on the average preferences shows that the best companies have very specific skills, highlighted by the fact that their profile generally presents a preponderance of particular processes. These skills, be they production, innovation and organisational/managerial, are more or less important in function of the type of relation undertaken. When the customers company is oriented towards long-term relations of a predominantly strategic nature, project management and organisational skills become fundamental, while production skills remain a pre-requisite.

A cluster analysis at processes level is used to divide the sample into homogenous classes and identifying the processes underlying each class; it was so possible to derive both the type of relation that each company is able to undertake and the processes on which the latter must work in order to be able to enter a more developed relationship. Detection and improvement of critical areas, but also identification of strengths, is a requirement for supplier firm, that can allows to evaluate and to develop advantageous relationships with its customers. Each firm must develop and implement a specific action plan, which needs to be aligned with company's business environment, positioning, capabilities and organisational structure; but we try to identify groups of firms with the same characteristics and to draw up their critical areas. The final result is thus the identification of different "development paths" allowing suppliers, with time, to undertake more complex and integrated relations with their clients by focusing on improvements in those 
processes and enabling factors which primarily determine the success of one specific relation.

Application of the model using the customer companies' average preferences and field data from suppliers gave a set of variables that allows to describe each supplier company within the sample: it is composed by the final overall score, processes values, assets values and further down until single data level. For the analysis only the first and second level are used, i.e. overall score and processes values.

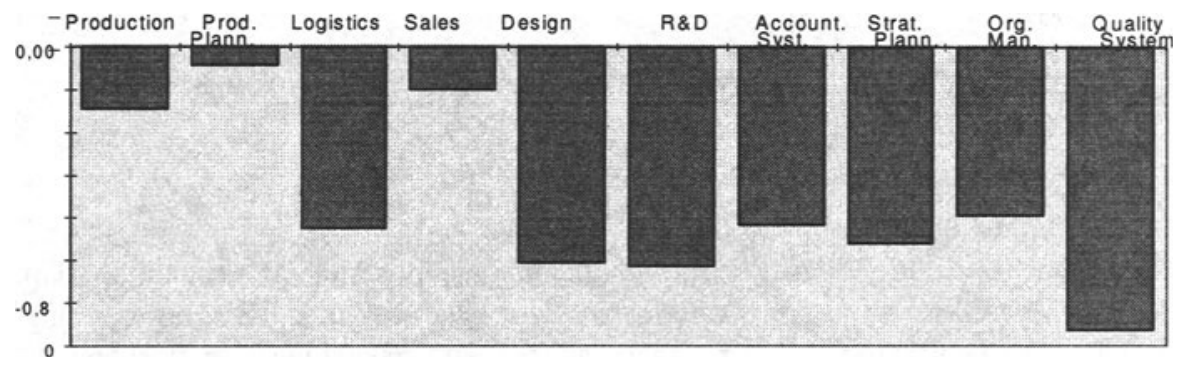

Figure 4 Poor companies profile.

First, a cluster analysis was used to uncover homogeneous groups of suppliers firms. The processes values were used as the criterion-variables. The K-means method was implemented, using the VRC index (variance ratio criterion) to determine the appropriate number of clusters. Then a ANOVA was implemented to test the groups. Table 3 in the next page reports the results of the cluster analysis: four different typologies of suppliers firms emerged and their characteristics in terms of processes values are analysed. Within each class, the points score for the processes and the overall score (i.e. the weighted average of the scores of the processes) were analysed. Next, representative profiles for each class were identified. There is a general improvement on the overall score and on the processes values in the move from one class to the next higher one in terms of overall score, so for the sake of simplicity the classes are referred to below as "excellent companies", "good companies", "fair companies" and "poor companies".

The first cluster includes "poor firms" with the average profile completely below the zero. The logistics, design, R\&D and, above all, Quality System processes are particularly critical in this profile, while production, production planning and sales are more favourable. This is explained by the fact that production and related processes are always of central importance for SMEs, even if formalised procedures are not followed (Figure 4). 


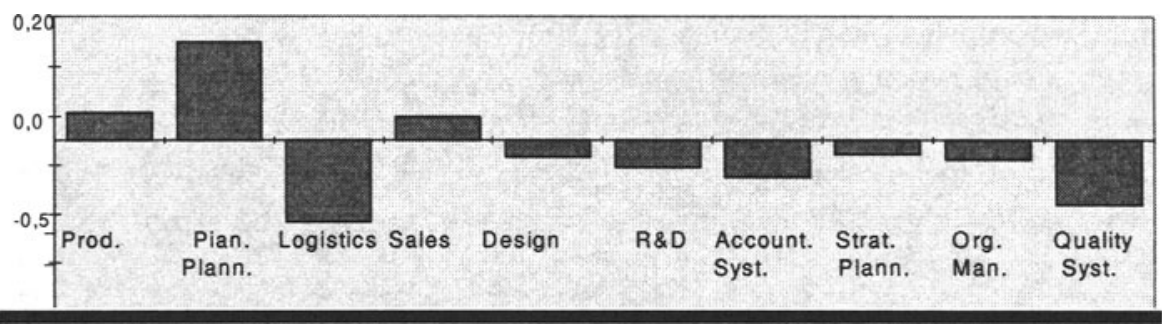

Figure 5 Fair companies profile.

A first difference can be noted in analysing the mean profile of "fair" companies or second cluster illustrated in Figure 5. Two trends are evident from the average scores of second cluster or "fair" companies. First, the profile is generally much better than previous cluster. All processes obtain higher scores than in "poor" companies, although the level of improvement varies. The largest increase is in production planning. This process is a lever that can control and optimise performance which has an impact on the final customer, e.g. delivery reliability or order time.

Figure 6 shows the average scores of third cluster or "good" companies. A general improvement is evident in all the processes, but the critical points remain logistics, R\&D and design. On the other hand, there is a clear improvement in the Quality System score. "Good" companies are more skilled in formalising and utilising methodologies in support of all activities. These skills are introduced and stimulated throughout the company by the spread of a quality-based culture. The improvement in this process therefore has synergetic effects with other company processes, e.g. production, management and organisation.

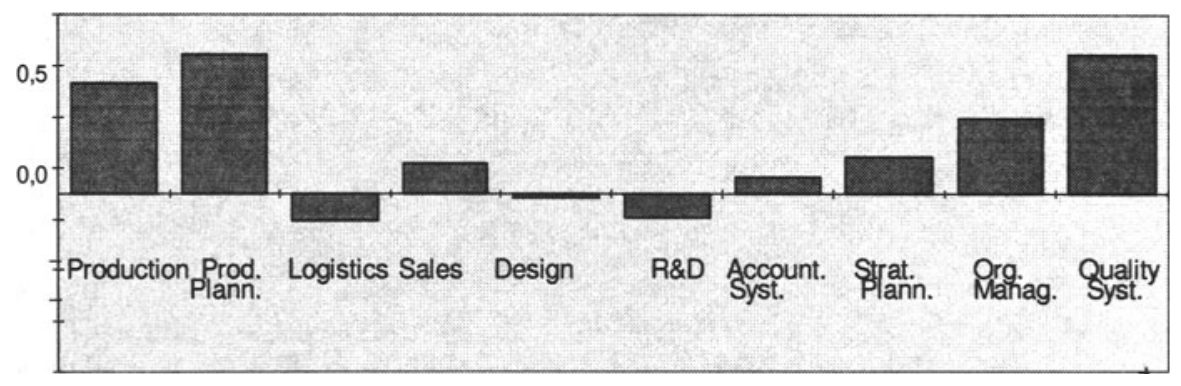

Figure 6 Good companies profile.

The noticeable improvement in the profile of "good" companies is confirmed and heightened in the excellent ones or last cluster (Figure 7). All processes have high scores. Over and above management of the Quality System and operational processes mentioned above, these companies are also skilled in design and strategic planning. In consequence, they are in a position to draw-up medium and long-term 
plans, making them more suitable and potentially capable to undertake partnership relations with customer companies.

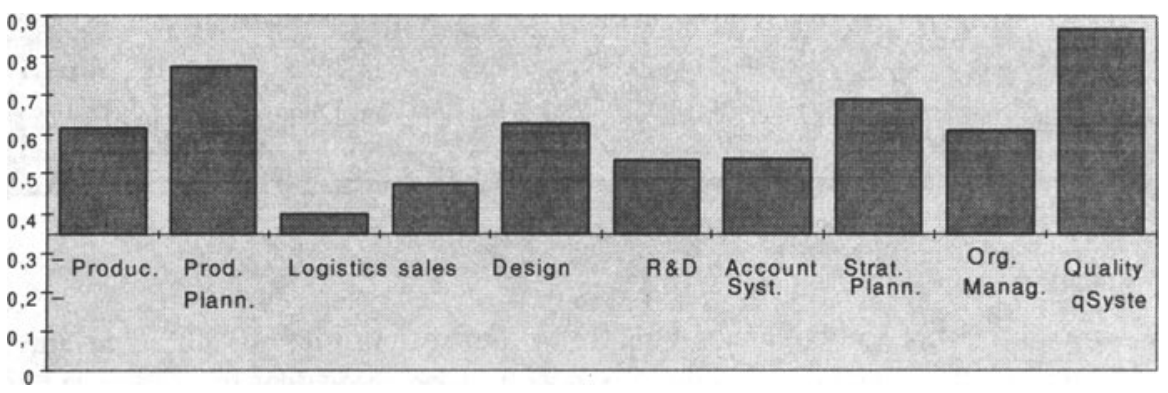

Figure 7 Excellent companies profile.

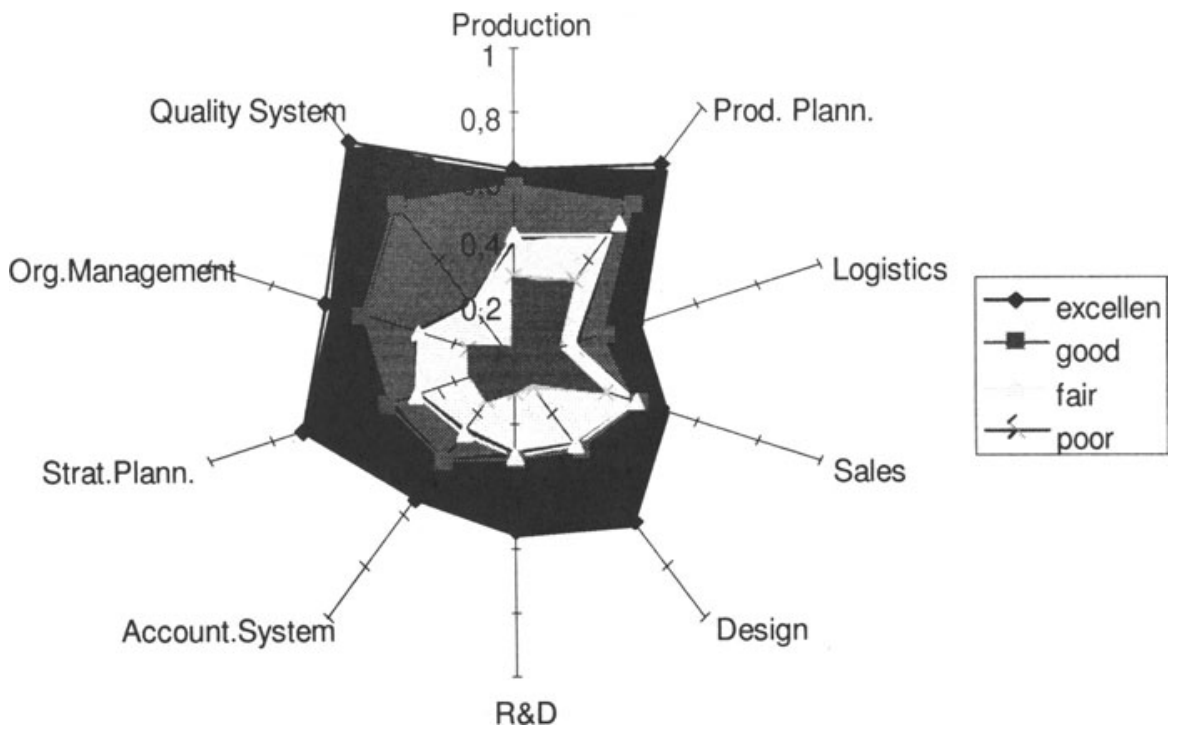

Figure 8 General view: radar graphs of the classes.

Having analysed the main characteristics of the average profiles, an overall view of the comparative scores is showed in the graph below, where are well represented strengths and weakness of different clusters of firms.

The analysis of variance was performed to investigate more quantitatively differences among clusters. The Scheffé test was used to test between means (it is more conservative than other tests, as Tukey HDS). The figure in the next page shows which processes have a better statistically significant difference among the fourth clusters or groups of firms.

This processes can be viewed as the critical areas that a firm must develop to improve overall performance, but also a sort of "development path" allowing sup- 
pliers, with time, to undertake internal organisational change and process re-engineering, that allows to meet the requirements of its customers. Understanding and commitment on customers needs can be translate into focusing on improvements in those processes, looking at the good practices in processes of the best firms.

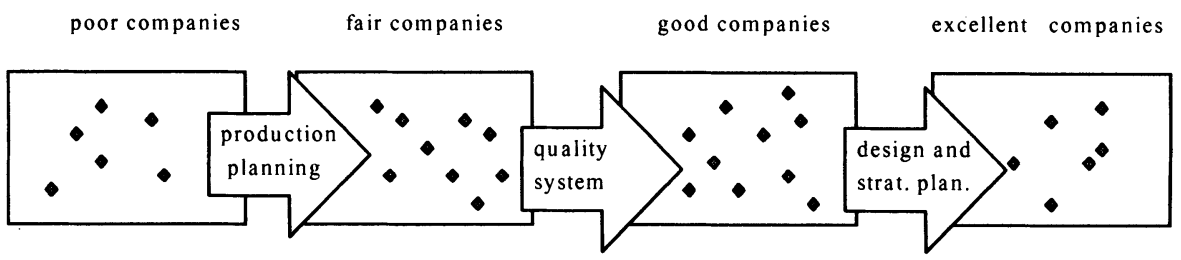

Figure 9 The "development path" for supplier companies.

\section{CONCLUSIONS}

The paper offers a view of sub-contracting in Southern Italy: the evaluation of the individual processes and a number of relevant assets revealed that the four classes of company represent groups with comparable internal skills. This led to the drafting of a sort of "growth path", in which promotion to a higher class depends on the strengthening of various fundamental processes.

Another conclusion concerns the general relevance of the study. Without forgetting the present context, the results can be generalised beyond Southern Italy. Above all, the procedure used could be adopted for the selection of suppliers, drawing attention to the processes and variables necessary to establish a certain type of relation. Moreover, companies could use the methodology and results obtained to diagnose the critical factors responsible for unsatisfactory performance, and so intervene to define appropriate actions for enhancing the firm's performance.

The research is still in the development phase. A subsequent, in-depth study will look at relationship between individual processes and assets/enabling factors and their impact on overall process performance: in particular, the forecasting value of processes discussed here will be treated further; will be also analysed the possibility of existence of different growth paths for SMEs also linked to the different position of firms in a supply chain; further extension of the work will consider also different sectors and industrial contexts.

\section{REFERENCES}

Amit, R. and Shoemaker, P.J. H. (1993) Strategic assets and organisational rent. Strategic Management Journal, 14, 33- 46.

Bartezzaghi, E. Spina, G. and Verganti, R. (1994) Nuovi modelli d'impresa e tecnologie di integrazione. Franco Angeli. 
De Maio, A. and Maggiore, E. (1992) Organizzare per innovare. Rapporti evoluti clienti-fornitori. Etas Libri, Milano.

Dickson, G.W. (1966), An analysis of supplier selection of supplier selection systems and decisions. Journal of purchasing, 2, 5-17.

Edwards, C. and Peppard, J. (1994) Forging a Link between Business Strategy and Business Reengineering. European Management Journal,Vol.12, 4, December.

Ellram, L. M. (1990) The Supplier Selection Decision in Strategic Partnerships. Journal of Purchasing and Materials Management, Fall 1990, 8-14.

Esposito, E. and Lo Storto, C(1992) Il sistema della subfornitura. Sviluppo e Organizzazione, 130, Marzo-Aprile.

Grant, R. M.(1991) The resource-based theory of competitive advantage: implications for strategy formulation. California Management Review, Spring 1990, $114-135$.

Hamel, G. and Prahalad C.K. (1990) The Core Competence of the Corporation. Harvard Business Review, May-June 1990, 79-91.

Harland, C. M. (1996) Supply Chain Management: Relationships, Chains and Networks. British Journal of Management, 7, 63-80.

Hartley, J.and Choi, T. (1996) Supplier Development: Customers as a Catalyst of process change. Business Horizons, July-August 1996, 37-44.

Kauffman, R.G. (1994), Influences on Industrial buyers' choice of products: effects of product application, product type and buying environment. International Journal of Purchasing and Materials Management, spring, 29-38.

Klir, G. J.and Yuan B.,(1995) Fuzzy sets and fuzzy logic - Theory and applications. Prentice-Hall, Upper Saddle River, New Jersey.

Kolay, M. K. (1993) Suppliers Asset Base - Appreciating or Depreciating? International Journal of Operations \& Production Management, 8, 1993, 72-86.

Lamming, R. (1993) Beyond Prtnerships: Strategies for Innovation and Lean Supply. Prentice-Hall, Hemel Hampstead.

Lamming, R. (1996) Squaring lean supply with supply chain management, International Journal of Operations \& Production Management, 16, 2, 183-196.

Landeros, R., Reck, R. and Plank, R.E. (1995) Maintaining buyer-supplier partnerships. International journal of purchasing and material management, summer, 3-11.

Mendez, E. G. and Pearson, J.N. (1994) Purchasing's Role in Product Development: the case for time-based strategies. International Journal of Purchasing and Material Management, Winter, 3-12.

Mohanty, R. P.and Deshmukh, S.G., (1993) Use of Analytic Hierarchic Process for Evaluating Sources of Supply. International Journal of Physical Distribution \& Logistics Management, 23 (3), 22-28.

Morlacchi, P.and Savoldelli, A. (1997) Supply Chain Management in Italian Machinery and Plants Industries. $4^{\text {th }}$ Euroma Conference, Barcellona, 1997.

Nassimbeni, G. De Toni, A. and Tonchia, S. (1993) L'evoluzione dei rapporti di subfornitura. Sviluppo e organizzazione, 137, Maggio/Giugno, 96-107. 
New, S. (1996) A framework for analysing supply chain improvement. International Journal of Operations \& Production Management, 16, 19-34.

Ostroff, F. and Smith, D, (1992) The horizontal organization. The McKinsey Quarterly, 1, 148-168.

Pavesi, S.and Savoldelli, A. (1997) Supplier-Customer relationships and business process organisation of the firms. $6^{\text {th }}$ IPSERA Conference, Ischia, 1997.

Saaty, T. L. (1986) Axiomatic foundation of the analytic hierarchy process. Management Science, 32 (7), July 1986, 841-855.

Smeltzer, L.(1997) The meaning and origin of trust in buyer-supplier relationships. International Journal of Purchasing and Materials Management, winter, 4048.

Soukup, W. (1987), Supplier selection strategies. Journal of Purchasing and materials management, 23, 2, 7-12.

Soukup, W. R. (1988) Strategie di selezione del fornitore. Logistica d'impresa, 62febbraio.

Stamm, C. L. and Golhar, D. Y. (1993) JIT purchasing: attribute classification and literature review. Production planning and Control, 4, 3, 273-282.

Thompson, K.N.(1990) Vendor profile analysis. Journal of purchasing and materials management, winter, 11-18.

Timmermann, E.(1986), An approach to supplier performance evaluation. Journal of Purchasing and Materials Management, 22, 4, 2-8.

Weber C.A., Ellram L.M. (1992), Supplier Selection using multi-objective programming: a decision support system approach, International Journal of Physical Distribution and Logistics Management, 23, 2, 3-14.

Weber, C. A, Current, J. R. and Benton, W.C. (1991) Vendor selection criteria and methods. European journal of operational research, 50, 2-18.

Willis, T. H. and Huston, C. R. (1992) Supplier certification: concepts and techniques. Logistic Information Management, 5, 1, 32-38.

Wilson, E.J. (1994) The relative importance of supplier selection criteria: a review and update. International Journal of Purchasing and Material Management, Summer, 35-41.

\section{BIOGRAPHY}

Pierangela Morlacchi is Researcher at Production \& Logistics Centre, Consorzio MIP, Politecnico of Milan. Her reserch interests include supply chain management and supplier development.

Sara Pavesi is Researcher at Production \& Logistics Centre, Consorzio MIP, Politecnico of Milan. Her reserch interests include supply chain management and strategic purchasing.

Alberto Savoldelli is Senior Researcher at Production \& Logistics Centre, Consorzio MIP, Politecnico of Milan. His reserch interests include supply chain management and strategic purchasing. 